\title{
ROMANIAN
}

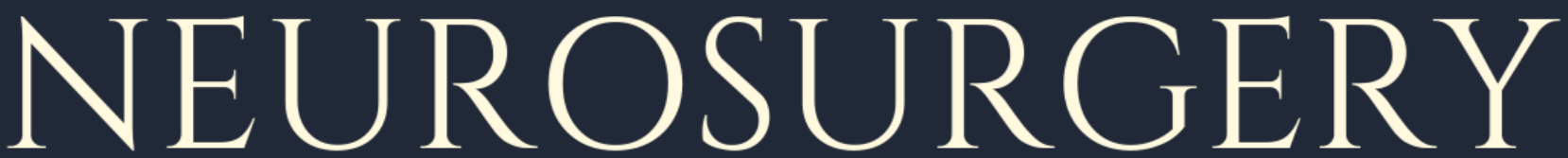

\author{
Vol. XXXIV | No. $1 \quad$ March 2020
}

\section{Intraventricular arachnoid cyst of lateral ventricle in an elderly patient}

\author{
Rajneesh Misra, \\ Sushil Kumar, \\ Sandeep Sharma, \\ Pankaj Bharadva
}




\title{
Intraventricular arachnoid cyst of lateral ventricle in an elderly patient
}

\author{
Rajneesh Misra, Sushil Kumar, Sandeep Sharma, \\ Pankaj Bharadva
}

St. Stephens Hospital, Tis Hazari, Delhi, INDIA

\begin{abstract}
Arachnoid cysts are usually located in relation to the arachnoid cisterns. Intraventricular location is rare and its embryological emergence in this site is controversial. We report a large intra-ventricular cyst in a 61-year-old female who presented with decreased vision, headache and right hemiparesis. MRI was suggestive of cystic lesion in the lateral ventricle and was excised completely through a craniotomy.
\end{abstract}

\section{INTRODUCTION}

Arachnoid cyst comprises about $1 \%$ of intracranial space occupying lesions and are located in relation to arachnoid cisterns, most common locations being sylvian, chiasmatic, suprasellar, quadrigeminal and cerebellopontine cisterns. Symptomatic presentation of an intraventricular arachnoid cyst is very rare especially in the seventh decade of life and hence it being reported.

\section{CASE REPORT}

A 61-year-old lady presented with decreased vision and headache of about one-year duration and weakness in the right side of the body for the preceding two and half months.

On examination: She was conscious; visual acuity was limited to perception of light in the right eye and finger counting at a distance of $2 \mathrm{ft}$ in left eye. There was increased tone in all limbs and right hemiparesis with a power grade III. A retinal hole had been detected in the right eye in another hospital.

Investigations: routine blood investigations, urinalysis, kidney function, liver function, ECG were reported to be normal. MRI of the brain revealed a large lesion, hypo-intense on T1WI and hyper-intense on T2WI suggestive of cystic mass in the lateral ventricle (Fig 1).

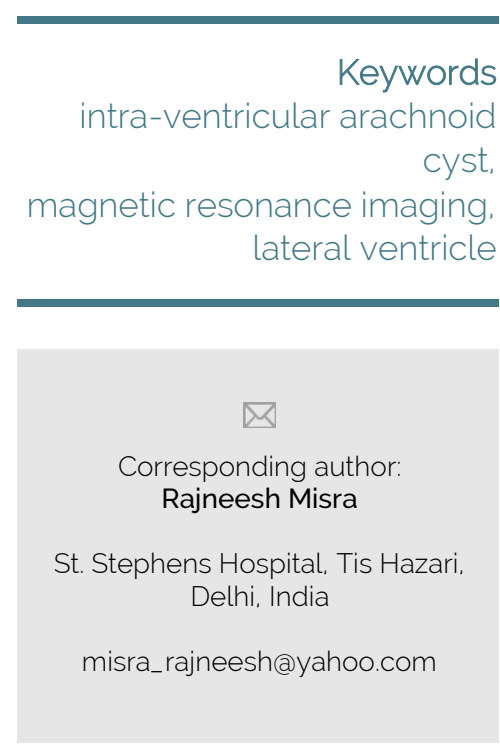

Copyright and usage. This is an Open Access article distributed under the terms of the Creative Commons Attribution Non-Commercial No Derivatives License (https://creativecommons org/licenses/by-nc-nd/4.0/) which permits noncommercial re-use, distribution, and reproduction in any medium, provided the original work is unaltered and is properly cited.

The written permission of the Romanian Society of Neurosurgery must be obtained for commercial re-use or in order to create a derivative work.

ISSN online 2344-4959 (C) Romanian Society of Neurosurgery

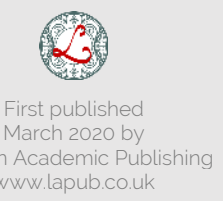


Craniotomy revealed large ventricle containing well defined thin walled cyst which could be easily separated from the ependyma. It was excised in-toto after coagulation of its attachment to the vessels. Histopathology of the cyst wall confirmed it to be arachnoid cyst.
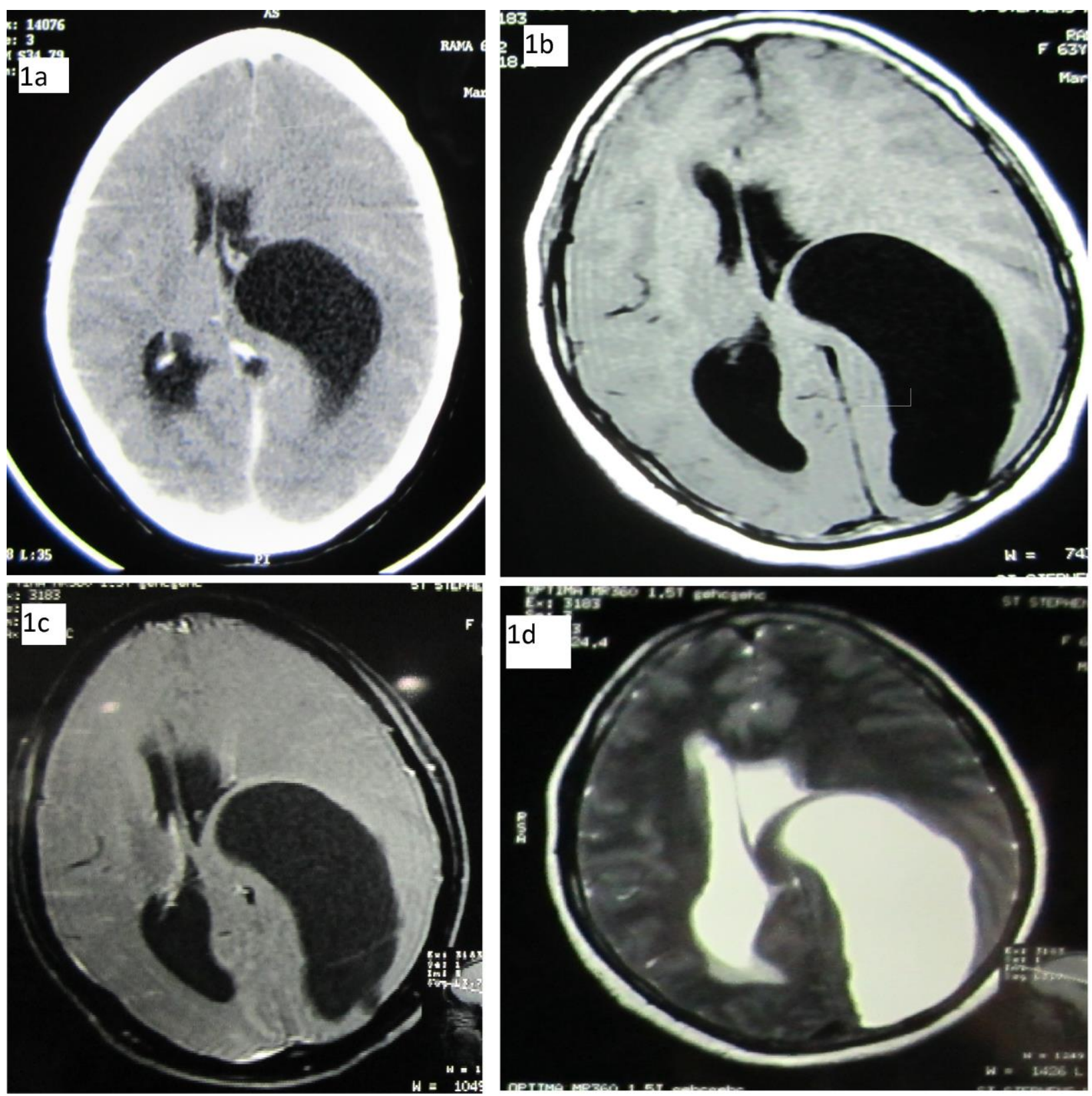

Figure 1. Showing imaging characteristics of the intraventricular arachnoid cyst. On contrast CT (1a), it shows no enhancement of the cyst wall. The cyst is hypointense on T1 (1b), hyperintense on T2 (1d) with no wall enhancement on T1 contrast (1c).

\section{DISCUSSION}

Most of the arachnoid cysts are asymptomatic and are discovered incidentally on imaging for other indications (1). When they are symptomatic, the
Postoperatively her vision improved to finger counting at $6 \mathrm{ft}$ and regained full power in the right sided limbs. Her vision continued to improve over the period of observation to $6 / 16$ and $6 / 24$ which could be improved to $6 / 9$ with glasses. 
were adults and 8 were children. Headache was the most common presenting feature in this series. Wong et al in 1993 reported a case which presented with positional psychosis due to intermittent blockage of temporal horn that occurred when the patient had been recumbent for $2-3$ hours ${ }^{(3)}$. Focal neurological deficits like hemiparesis as seen in our patient are rare at presentation. These lesions are seen usually in children or in the 4th decade of life. Recently, relatively large series of pediatric patients treated endoscopically have been published (4). However; our patient seems to have been the oldest in the $7^{\text {th }}$ decade of life. What process had altered the status quo between the cyst and the patient is debatable as she had been apparently living with it for almost all of her life.

There are primarily two theories about the embryological origins of the arachnoid cysts. The first is the 'arachnoid splitting theory' ${ }^{(5)}$. As the name suggests, it proposes that these cyst $s$ arise as a result of congenital splitting of the arachnoid layer wherein, the CSF accumulates gradually. The other theory is in specific context of middle cranial fossa arachnoid cysts and suggests that these arise as a result of temporal lobe agenesis as the primary event. However, it is named as 'subarachnoid cyst theory' (6).

There are various mechanism proposed for expansion of the arachnoid cysts. These include, but are not limited to, fluid secretion by cyst wall, presence of osmotic gradient and ball valve mechanism ${ }^{(7)}$.

As mentioned previously, arachnoid cysts are purported to arise by a congenital splitting of the arachnoid membrane and subsequent accumulation of CSF in this 'potential space'. However, normally, there is no arachnoid tissue in the ventricle. Thus, the origin of an arachnoid cyst in intraventricular location is controversial. According to Yeates and Enzmann, intraventricular arachnoid cysts arise from the vascular mesenchyme by invagination into adjacent brain, picking up an outer covering of adjacent glial tissue ${ }^{(8)}$. Nakase et al. postulate that cyst arises from the arachnoid layer brought with vascular mesenchyme which it invaginates via the choroidal fissure ${ }^{(9)}$. Usually, the cysts are located in the occipital horn and/or trigonal region and cause dilatation of the temporal horn and/ or occipital horn. In our patient, the cyst pathogenesis seems to mirror the mechanism proposed by Nakase et al. as it had an attachment to the choroidal fissure.

Imaging characteristics are those of any CSF containing cavity viz. hypo-intense on $\mathrm{T} 1$, hyperintense on $\mathrm{T} 2$ and without any contrast enhancement. Symptomatic cysts require surgical intervention. The options available include endoscopic fenestration, cyst de-roofing, partial or complete removal and cysto-peritoneal shunt. Our patient was treated by complete removal of cyst wall through a craniotomy. Endoscopic fenestration was the safer and less invasive option. In Park's series, there were various combinations and permutations of procedures applied for management of adult as well as pediatric intraventricular arachnoid cystsopen removal, open fenestration or partial cyst removal and endoscopic fenestration and shunt ${ }^{(2)}$. Kurokawa et al recommended cyst resection rather than shunt because he found that the size of the ventricle was not reduced after the shunt procedure and the shunt malfunctioned due to wrapping of the shunt by the collapse cyst ${ }^{(10)}$. Park et al had case of large arachnoid cyst of the lateral ventricle extending from the suprasellar cistern. The cyst wall could be easily separated from the ventricular ependymal after coagulation and transection of the attachments.

Cysto-peritoneal shunt or complete removal of the cyst wall are necessary to prevent recurrence, whereas cyst opening alone is insufficient. Our patient was treated by complete removal of the cyst wall through a craniotomy to avoid recurrence.

\section{CONCLUSIONS}

The embryological origin of intraventricular arachnoid cysts is controversial and the jury is still out. Our intraoperative observation during the cyst excision had shown the cyst to have an attachment to choroid fissure of the left lateral ventricle. This is in agreement with Nakase et al.'s propounded theory that intraventricular arachnoid cyst arises from the arachnoid layer brought with vascular mesenchyme which it invaginates via the choroidal fissure.

\section{ReferenCES}

1. Al-Holou WN, Yew AY, Boomsaad ZE, Garton HJ, Muraszko KM, Maher CO. Prevalence and natural history of arachnoid cysts in children. J Neurosurg Pediatrics 2010; 5:578-585. 
2. Park SW, Yoon SH, Cho KH, Shin YS. A large arachnoid cyst of the lateral ventricle extending from the supracerebellar cistern-case report. Surg Neurol. 2006 Jun;65(6):611-4.

3. Cheuk-Wah Wong, Sheung-Fat Ko, Yau-Yau Wai, Arachnoid Cyst of the Lateral Ventricle Manifesting Positional Psychosis, Neurosurgery, Volume 32, Issue 5, May 1993, Pages 841-843.

4. Copley, P., Kirkman, M.A., Thompson, D. James G, Aquilina K. Endoscopic surgery for intraventricular arachnoid cysts in children: clinical presentation, radiological features, management, and outcomes over a 12-year period. Childs Nerv Syst (2018) 34: 257.

5. Starkman SP, Brown TC, Linell EA: Cerebral arachnoid cyst. J Neuropathol Exp Neurol 17:484-500, 1958.
6. Robinson RG: Congenital cysts of the brain: arachnoid malformations. Prog Neurol Surg 4:133-174, 1971.

7. Basaldella L, Orvieto E, Dei Tos AP, Della Barbera M, Valente $M$, Longatti $P$. Causes of arachnoid cyst development and expansion. Neurosurg Focus. 2007;22(2): E4.

8. Yates A, Enzman D. An intraventricular arachnoid cyst. J Comp Assist Tomogr 1979; 3:697-700.

9. Nakase $H$, Hisanaga $M$, Hashimoto $S$, Imanishi M, Utsumi S. Intraventricular arachnoid cyst. Report of two cases. J Neurosurg 1988; 68:482-6.

10. Kurokawa Y1, Sohma T, Tsuchita H, Kitami K, Suzuki S, Ishikawa A. A case of intraventricular arachnoid cyst. How should it be treated? Childs Nerv Syst. 1990 Sep;6(6):3657. 